\title{
Negation of subject with nominal modifiers in Sesotho
}

\author{
Elias Nyefolo Malete \\ Department of African Languages, University of the Free State, South Africa \\ E-mail: maleteen@ufs.ac.za
}

\begin{abstract}
This article examines constituent negation in Sesotho, focussing on negation of the subject with nominal modifiers of matrix clauses. Sesotho is an African language that falls under the Bantu family. Unlike English, which makes use of negative elements to negate clausal constituents, such as no in no children have eaten, Sesotho does not have a direct means of negating a clausal constituent. The central aim of this article is to demonstrate how Sesotho employs negative clauses, such as negative cleft sentences, negative pseudo-cleft sentences and negative clauses, together with the marker ho, to realise constituent negation. This article will also argue that, in terms of Haegemen's (1995) Neg-Criterion, Sesotho does not have non-negative operators that could constitute the realisation of local or constituent negation.
\end{abstract}

Keywords: constituent negation, cleft sentence, nominal modifiers, pseudo-cleft sentence, Sesotho, subject

\section{Introduction}

Sesotho is one of the eleven official languages of South Africa, spoken in Lesotho and South Africa. It is a highly agglutinative language and falls within the Bantu family, forming a Sotho cluster with Setswana and Sepedi. Sesotho has no direct means of negating a clausal constituent, unlike languages such as English, which make use of negative words like no in no children have eaten. The aim of this article is to demonstrate that, in Sesotho, negative clauses, rather than negative words or non-negative operators, negate the subject argument of matrix clauses. Clauses negating the subject argument with nominal modifiers are realized by negative cleft sentences, negative pseudo-cleft sentences and negative clauses with AGRS, ho. These three clauses must appear with a contrastive clause in order to put the subject argument in context. Constituent negation in Sesotho is therefore a contextualized type of negation.

Negation of subject arguments will be considered within the framework of the Minimalist Program, which maintains that a language consists of the lexicon and the computational system, where the operations Merge and Move generate sets of structural descriptions. It is driven by the principle of Economy, which stipulates that movement should take place only when necessary for the purpose of case checking. This theory is also concerned with the expansion 
of syntactic structures in terms of X-bar theoretic properties, where functional categories are given full categorical status.

Freidin (1995) describes the Minimalist Program as the theory that reconstructs certain parts of linguistic theory, which are based on speculations about language design and how it might accommodate the architecture of the mind. It seeks to limit the theory of language grammar to what is conceptually necessary. The phrase structure component is reduced to a fundamental part of transformational component and modular sub-components of Universal Grammar such as Government theory, Case theory, Binding theory and trace theory are eliminated or reduced in favour of Economy conditions and bare output conditions.

Haegeman (1997) further states that an important feature that determines the properties and distribution of clauses is the nature of the verb inflection. The inflection properties of a sentence are represented by inflection, a functional head that encodes inflectional features such as Agreement, Tense and Mood. In recent developments of the theory, inflectional features are separated and turned into phrasal categories, where their morphemes become heads of such phrases. For instance, the phrases AgrP, TP and MP have Agreement, Tense and Mood morphemes as heads. All the inflectional categories are above the VP lexical domain and are referred to as Functional Categories and their heads as Functional Heads. A split Inflection results in functional projections, such as NegP for the expression of sentential negation, and AgrP, separated into AgrSP for subject agreement and AgrOP for object agreement. The aspectual features also have their own projection, namely AspP.

Sesotho negative clauses have a functional projection, called a Negative Phrase, which has the negative morphemes /ha/, /sa/, and /se/ as heads. This will be discussed further in section 3 . With regard to subordinate clauses, the negative phrase has either $/ \mathrm{sa} / \mathrm{or} / \mathrm{se} /$ as head because they are the only two negative morphemes used in Sesotho subordinate clauses. With regard to matrix clauses with non-copulative verbs, the negative morpheme employed in Sesotho is [ha], where it co-occurs with the negative suffix [-e], and with regard to copulative verbs [ke] and [LI], Sesotho employs the negative morpheme [ha], where it co-occurs with the negative copulative verb [se] as [ha-se]. It is also noted that the negative morpheme [ha] does not appear with any agreement morpheme when it co-occurs with the negative copulative verb [se]. For the purpose of this discussion, the focus will be on the negative morpheme [ha]. The morphological structure of the negative morpheme [ha], where the negative [se] appears as the verb is shown in the structure in (1) below.

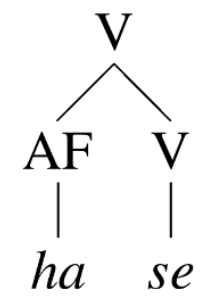

The explanation and representation in (1) above is crucial in this discussion, as all negative clauses, which are used to negate the subject constituent, have this combination. It is also necessary to give an overview of grammatical concepts such as the notion 'subject' and its 
structural position, the nominal modifiers in Sesotho, the notion 'negation' and in particular constituent negation and demonstrate how negative clauses such as negative cleft sentences, negative pseudo-cleft sentences and clauses with marker [ho] are used in Sesotho to achieve constituent negation.

\section{Subjecthood}

Richards (1985) defines the subject as the nominal entity performing the action described by the verb. Haegeman (1997) and McCloskey (1997) regard subjecthood as central because there is a broad range of reference to it. These references can be considered as properties and functions of the subject, which can help to give a clear description of the subject. According to McCloskey (1997) and Haegeman (1997), the subject has categorial information which specifies that subjects are nominal, thematic information which specifies that the subject is a prototypical bearer of the agent theta-role and, to a lesser extent, that of theme and experiencer. It has hierarchical information that identifies the subject as the prominent DP/NP argument of the verb in that it takes a wider scope. They further point out that the subject is obligatorily present in the clause, whether it be a contentive or null subject, and has morphological information, which describes the subject as the nominal that has nominative case and agreement morphology.

Furthermore, Cardinaletti (1997) gives a distinction between post-verbal subjects and preverbal subjects. Pre-verbal subjects can be realized as either overt subjects or null subjects. Null subjects are deficient pronouns, as opposed to strong pronouns, and are represented by [pro]. Overt subjects are ordinary subjects, which are phonologically represented in the sentence. Du Plessis and Visser (1995), go further and differentiate between specified and unspecified subjects: specified subjects are nouns with identifiable referents based on the semantic interpretation of the sentence while unspecified subjects are not identifiable.

The subject argument in Sesotho conforms to the notions and principles described by Richards (1985), McCloskey (1997), Haegeman (1997) and Cardinaletti (1997) above, in that Sesotho subjects are pre-verbal, there are strong overt subjects, which are further classified as unspecified subjects or specified subjects. There are also empty or null subjects in Sesotho, which are phonologically absent but syntactically present due to strong verbal morphology of Sesotho.. The following sentences illustrate the different types of subjects in Sesotho.

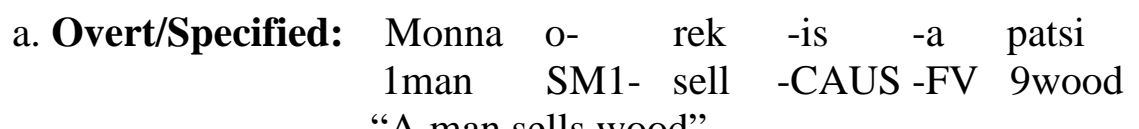

"A man sells wood"

$\begin{array}{lllll}\text { b. Null subject: } & \text { O- rek } & \text {-is } & \text {-a } & \text { patsi } \\ \text { SM1- sell } & \text {-CAUS } & \text {-FV } & \text { 9wood } \\ \text { "He sells wood" } & & & \end{array}$

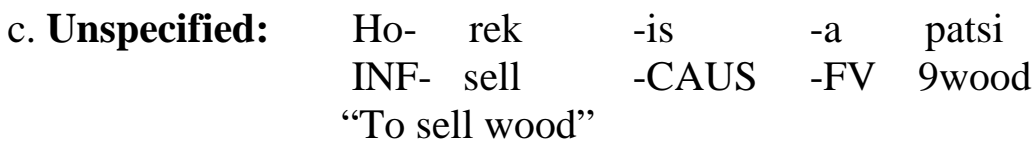

With the current developments in the theory, where TP heads sentence constructions, the subject in Sesotho still conforms to the split subject positions. With regard to nominal modifiers, 
Malete (1996) argues that nominal modifiers modify heads of noun phrases and are grouped as non-clausal nominal modifiers and clausal modifiers. In Sesotho, a noun phrase may be modified by a clause [CP], such as a relative clause, or by non-clausal modifiers, such as descriptive noun phrases, demonstratives, quantifiers, adjectival phrases and prepositional phrases. In this article, only adjectival phrases and relative clauses will be employed as examples of nominal modifiers.

\section{Negation}

Klima (1964) describes negation as part of the grammatical analysis of languages, consisting of grammar rules that are involved in sentences associated with negation as well as other parts of grammar common to negatives, e.g. interrogatives, restrictives and certain subordinate constructions. According to Klima (1964), sentence negation includes structures that permit the occurrence of the either-clause, the negative appositive tag and the question tag without [not]. It is characterized by the presence of the pre-verbal particle [Neg] in the sentence as part of the auxiliary. Lasnik (1974) describes negation as involving the distribution of the lexical [not] in the surface structure and the implications of the base rules and transformations involved in sentences containing [not]. He shares the same view with Klima (1964) about the position of the negative [not] in the sentence, but with him, both the sentence-initial position and the auxiliary position of [not] require auxiliary base position.

Negation is further categorised into sentence negation and constituent negation. According to Klima (1964), sentence negation is realized when negative pre-verbal particles are present in the sentence. Haegeman (1995) goes on to state that negative constituents that trigger subject inversion, have sentential scope and are referred to as negative operators. Negative operators express sentential negation. Haegeman (1995)'s analysis of sentence negation is based on the NEG-CRITERION, the well formedness condition that determines the distribution and interpretation of negative elements. Based on the Neg-Criterion, negative sentences are constructions, which minimally have Neg-feature, associated with a functional head of the extended projection of the verb. This implies that negative elements are identified as Negative Phrases (NegP) headed by a negative head, where the head is in geometrical position with its specifier as indicated in (3):

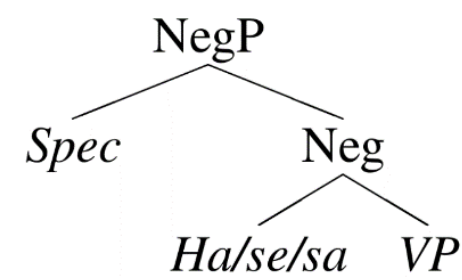

Zanuttini (1997) describes sentential negation as the syntactic process by which a language employs negative markers to negate a clause in order to express a negative proposition. In her analysis of negative markers, Zanuttini (1997) indicates that negative markers differ in terms of distribution and syntactic properties. She distinguishes three types of negative markers: Preverbal negative markers, Post-verbal negative markers and a combination of Post and Preverbal negative markers. Pre-verbal negative markers are negative markers that obligatorily 
precede the finite verb. In this category, there are pre-verbal negative markers that can negate a clause by themselves and those that cannot negate a clause by themselves but co-occur with other negative element to negate a clause. These two types of pre-verbal negatives differ with respect to pronominals, verbs, adverbs, negative imperatives and negative indefinites. Zanuttini (1997) goes on to point out that the projection NegP has strong features in the languages that express sentential negation by means of a pre-verbal negative marker that can negate a clause on its own. When the features are strong, a negative clause must have a negative marker in NegP and the strong features need to be checked. Zanuttini (1997) observes that when preverbal negative markers that can negate a clause by themselves are present in interrogative clauses, there is no verb movement if the word order is [Neg - subject - verb]. In other words, the subject clitic precedes the verb, but when the verb precedes the subject clitic, there is verb movement.

Ngonyani (2002), identifies six strategies of marking negation in matrix clauses of Bantu languages, viz., a preverbal particle, as in Hung'a, a pre-initial affix, as in Luba, a post-initial prefix, as in Nyakyusa, a post-final suffix, as in Nkoya, a post-verbal particle, as in Ngoyi and a pre-initial prefix + affix, as in modern standard Swahili. In support of Zanuttini (1997)'s structural positions of NegP in a sentence, he suggests two Neg positions for Bantu languages, viz., one position where the NegP selects TP and the other where TP selects NegP.

Tanda \& Neba (2005) state that in most of the Bantu languages, negative morphemes stand out clearly and coexist with other functional categories such as tense, aspect and mood. Sesotho conforms to their assertion in that the negative phrase has the negative morphemes $/ \mathrm{ha} / \mathrm{s} / \mathrm{sa} /$ and /se/ as heads. The negative morpheme [ha] in Sesotho is a pre-verbal negative morpheme with strong morphological features, it is a bound negative morpheme which precedes both the subject clitic and the verb and can negate the clause on its own as illustrated by the sentence in (4) and its structural representation in (5):
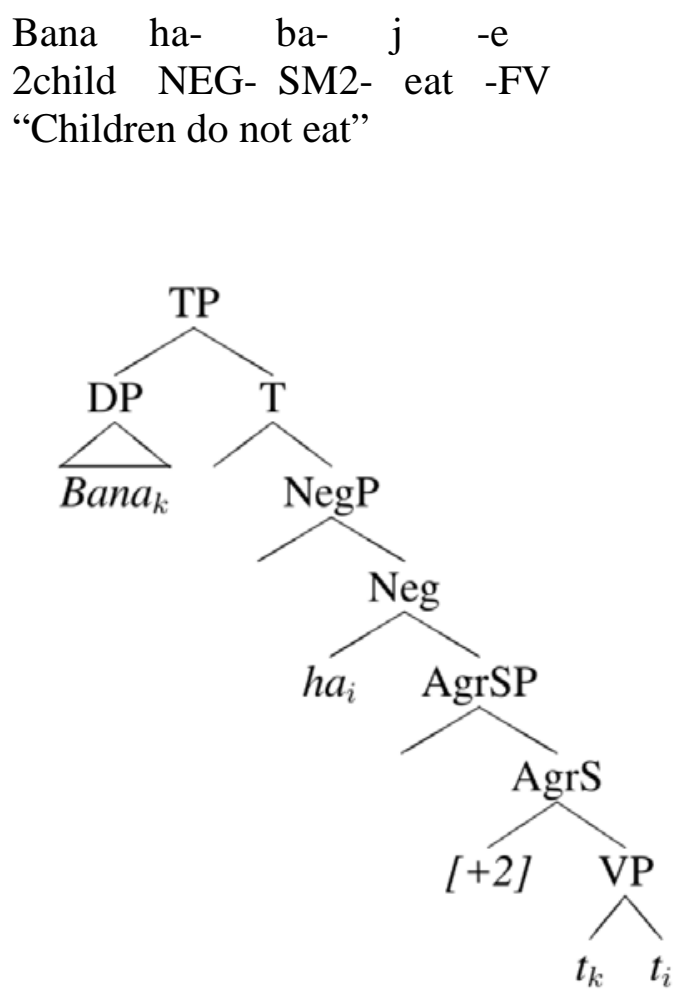
According to the structure in (5) above, the negative morpheme [ha] heads the negative phrase and it precedes both the subject agreement and the verb. However, the verb has to move to the negative morpheme as it has the negative feature in the form of the suffix [-e] to be checked. It is not necessary for the verb to check tense, as the present tense in Sesotho is not phonologically represented. The internal subject has to move to the specifier of tense to check its subject features. Madadzhe \& Matla (2002) deals with the negative morphemes /ha/ and /a/ in Sesotho and Tshivenda respectively, where they have indicated that these morphemes appear in sentences with constituents such as subjects, objects, verbs and aspect morphemes.

With regard to constituent negation, Haegeman (1995) states that pre-posed negative constituents that do not trigger subject inversion do not have sentential scope but constitute local negation and they are called non-negative operators. They are constituents such as not long after, not long ago, and such constituents do not qualify as operators. Klima (1964) describes constituent negation as characterized by the use of negative affixes such as /un-/, where the negative particle is treated as part of certain constituents as in the word unhappy. Mettouchi (2005), based on data from the Kabyle language, asserts that constituent negation is nonverbal and is used for local negation and for focalization. Laka (1974), in terms of the Determiner Theory, which stipulates that the particle /not/ be generated on noun phrases and adverbs as demonstrated in (6) below, further emphasizes this.

(6) a. [Not many] people arrived

b. [No man] will eat another

In (6) above, the scope of negation is restricted to the adverb many and the noun phrase man. It is a grammatical process referred to as constituent or local negation by Klima (1964), Haegeman (1995) and Laka (1974). In Sesotho, however, constituent negation, i.e. subject negation in this case, is achieved through a different grammatical process. Negative clauses and contrastive clauses, rather than non-negative operators, are used in realizing constituent negation in Sesotho. This is discussed in the following section.

\section{Negation of the subject with a nominal modifier}

As indicated earlier in our discussion, Sesotho has no direct means of negating a clausal constituent, as is the case with languages such as English, which make use of negative words like /no/ in no children have eaten. The central aim here is to demonstrate that in Sesotho the subject argument with nominal modifiers in matrix clauses is negated by negative clauses rather than by negative words. Three types of clauses are used to negate the subject with nominal modifiers, namely, negative cleft sentences, negative pseudo-cleft sentences and clauses with marker [ho].

\subsection{Negative cleft sentences}

According to Madadzhe (1997), cleft sentences are the identifying constructions expressing a relationship of identity between the element realized as the highlighted element and the relative clause. They are characterized by the phrase it is/was constructed from a simple or any underlying sentence. In form, the cleft sentence has two clauses that originate from the underlying sentence: these are the clause of focus, which is the identifying clause with the 
phrase it is/was and the relative clause, which put more emphasis and specificity on the clause of focus.

Negative cleft sentences in Sesotho can also be used to negate the subject argument with nominal modifiers, and in this case, only the adjectival phrases will be used to illustrate the process with intransitive verbs only as the outcome is the same with the other two kinds of verbs viz. transitive and ditransitive verbs. The clefted sentences, as indicated by Madadzhe (1997), are characterized by the focalized NP subject, which is introduced by the copulative verb [ke] in Sesotho and followed by the relative clause. In the negative, the copula [ke] is replaced by the negative morpheme [ha] and the negative copulative verb [se]. Three steps are involved to achieve this type of constituent negation in Sesotho:

Firstly, the subject argument with the adjectival phrase as nominal modifier appears with the intransitive verb construction as in (7) below:

$\begin{array}{lllll}\text { Bana ba } & \text { ba- } & \text { holo } & \text { ba- j } & \text {-ele } \\ \text { 2Child SM2 } & \text { NC2- } & \text { old } & \text { SM2- eat } & \text {-PST } \\ \text { "The older children ate” } & & & \end{array}$

Secondly, the cleft sentence is formed by the introduction of the copulative verb [ke] and the subject appears with the adjectival phrase and the verbal relative clause of cleft sentence as in (8) below:

Ke bana ba ba- holo ba- j -el
COP 2children SM2 NC2- old
"It is the older children who ate"

Du Plessis and Visser (1995), observe that the copulative verb [ke] mostly takes an NP as its complement and may never appear with any agreement or inflection. The purpose of the cleft construction, as in (8), is to put focus on this subject argument, i.e. to highlight this argument by means of a clause of focus. In Sesotho, this focus is effected by means of a copulative clause with the copulative verb [ke] as indicated in (8). With cleft constructions, the copulative clause does not appear with an overt subject but only with an empty [pro] because the cleft construction only accepts an empty [pro] as its subject as it needs to put focus on the subject argument. The verb in (8) above will appear in a relative clause to put focus on the subject.

According to Van Riemsdijk (2006), a relative clause is a clause that modifies a phrasal constituent, generally a NP. This NP is the head of the relative clause. Du Plessis (2010) further indicates that in the African languages of South Africa, the [NP] is the antecedent of the relative clause $[\mathrm{CP}]$. Within the relative clause [CP], these languages have a resumptive pronoun within [TP]. According to McCloskey (2006), quoted by Du Plessis (2010), the resumptive pronouns are variables with a binder which must be a null operator $[\mathrm{OP}]$ in the [Spec, $\mathrm{CP}]$ position. A relative clause in Sesotho will thus have the following structure:

$$
\begin{aligned}
& {\left[\text { bana }_{i}\right]\left[\mathrm { ba } _ { \mathrm { i } } \left[\mathrm{pro}_{\mathrm{i}} \mathrm{a}_{\mathrm{i}}\right.\right. \text {-jel-ng] }} \\
& \text { "The children who have eaten" }
\end{aligned}
$$

In (9) above, the antecedent of the relative clause CP is bana "children", the [Spec, CP] position has the null operator [OP] which is the binder of the resumptive pronoun [pro], co-indexed with 
AgrS in TP. Coming back to the cleft sentence, if one looks at the result of cleft constructions in Sesotho as indicated in (8), we do find a clause of focus and a relative clause, but what we have in reality is a totally new clause, where the copulative clause now appears with an empty subject [pro] and a complement of the copula [ke], which is a noun phrase. This noun phrase consists of the head noun, a relative clause and the adjectival phrase as nominal modifiers.

To achieve negation of cleft sentence in (8) above, the negative morpheme [ha] obligatorily appears with the negative copulative verb [se] as [ha-se]. The copulative verb [ke] is replaced by a negative copulative verb [se] that appears with a negative morpheme [ha] as illustrated by the sentence in (10):

$$
\begin{aligned}
& \text { [pro] Ha- se bana ba ba- holo ba- j -el -ng } \\
& \text { NEG- COP 2child SM2 NC2- old SM2- eat -PST -REL } \\
& \text { "It is not older children who ate" }
\end{aligned}
$$

However, in (10) above, the scope of negation goes beyond the subject with its nominal modifier and stretches to include the verb of the relative clause. If this is the case, it does not seem possible to use a cleft construction to negate the subject argument in isolation. There are two possibilities to reflect on with regard to the negative clause in (10) above. The first possibility is that the context of the clause in (10) should be taken into account and it will be necessary to further employ a clause of contrast as indicated in (11) below.

$$
\begin{aligned}
& \text { [pro] Ha- se bana ba ba- holo ba- j -el -ng, } \\
& \text { NEG-COP 2child SM2 NC2- old SM2- eat -PST -REL } \\
& \text { ke basadi ba ba- holo } \\
& \text { COP 2woman SM2 NC2- old }
\end{aligned}
$$

"It is not the old children who ate, it is the old women"

In this context as demonstrated by the sentences in (11) above, the subject argument bana "children" with the nominal modifier ba baholo "old ones" has been placed in a focus position. The clause of contrast, ke basadi [ba baholo] "it is the old women", is now used to negate the subject argument. In this case, the nominal modifier is not contrasted. In order to include the nominal modifier, a contrastive nominal modifier has to be inserted as in (12).

$$
\begin{aligned}
& \text { [pro] Ha- se bana ba ba- holo ba- j -el -ng, } \\
& \text { NEG- COP 2child SM2 NC2- old SM2- eat -PST -REL } \\
& \text { Ke basadi ba ba- nyenyane } \\
& \text { COP 2woman SM2 NC2- young } \\
& \text { "It is not the old children who ate, it is the young women" }
\end{aligned}
$$

The second possibility is that the relative clause with an empty [pro] may appear as the subject of the copulative clause, as illustrated by the sentences in (13).

[pro] Ba- j -el -ng ha- se bana ba ba- holo SM2- eat -PST -REL NEG- COP 2child SM2 NC2- old "(Those) who ate are not children" 
In (13) above the subject argument with its nominal modifier, bana [ba baholo] "old children" is now on the periphery of the sentence and it been highlighted in the negative context. With this type of negative construction, the scope of negation includes both the subject and the modifier. However, this type of clause will still need a clause of contrast as in (14) below.

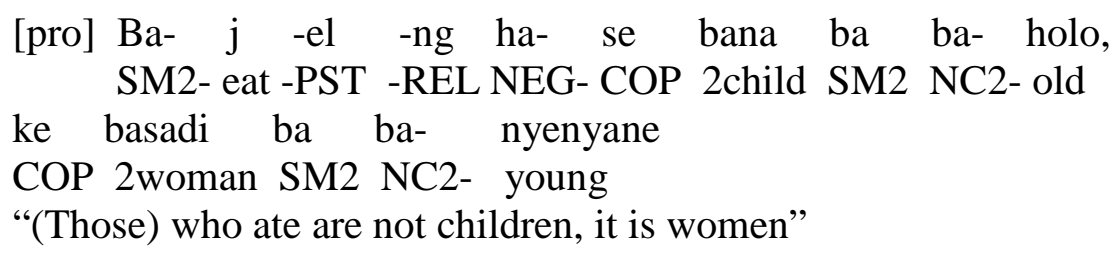

Thus the two types of clauses in (12) and (14) above, which both appear with the clause of contrast ke basadi ba banyenyane, will give the same interpretation of negation of the subject argument with nominal modifiers. The second type in (13) above is only a syntactic variation of the first type in (12). It should however be noticed that when the subject argument of the copulative clause is clefted, the subject is replaced by empty [pro] with subjectival agreement. In this way, constituent negation is realised by employing the negative cleft sentence with a contrastive clause.

\subsection{Negative pseudo-cleft sentences}

The second type of the clause to be examined is the negative pseudo-cleft sentence. Madadzhe (1997) describes the pseudo-cleft sentences as the copulative sentences where the subject clause is introduced by a wh-word. Pseudo-cleft sentences are characterized by a nominal relative clause introduced by [wh-] serving as the subject or theme. Madadzhe (1997) goes on to say that pseudo-cleft sentences and cleft sentences have the same semantic relationship because they both have a bipartite form. The bipartite form is brought about by breaking a simple sentence into a focal constituent and a relative sentence. The only difference, according to Madadzhe (1997), between a cleft sentence and a pseudo-cleft sentence is the position of the focal constituent. In a cleft-sentence, the focal constituent is in the initial position whereas in a pseudo-cleft, the focal constituent is in the latter part of the sentence. The sentences in (15) demonstrate this phenomenon in Sesotho.

$$
\begin{aligned}
& \text { a. Ke buka eo Thabo a- e- } \mathrm{f} \text {-ile -ng Mpho } \\
& \text { COP 9book DEM9 1Thabo SM1-OM9- give -PST -REL 1Mpho } \\
& \text { "It is the book which Thabo gave to Mpho" } \\
& \text { b. Seo Thabo a- se- } \mathrm{f} \text {-ile -ng Mpho ke buka } \\
& \text { DEM7 1Thabo SM1- OM7- give -PST -REL 1Mpho COP 9book } \\
& \text { "What Thabo gave to Mpho is the book" }
\end{aligned}
$$

The sentence in (15a) is a cleft sentence because the focal constituent ke buka "It is the book" is at the beginning of the sentence. The sentence in (15b) is a pseudo-cleft sentence because the focal constituent is in the latter part of the sentence. With pseudo-cleft sentences, the purpose is to establish whether it is possible to use them in negating the subject argument. There are three steps to follow in order to achieve negation of the subject with a nominal modifier. 
Firstly, the subject with adjectival phrase as its nominal modifier will appear in a simple sentence as shown in (16) below.

Ngwana e mo- holo o- fihl
1Child SM1 NC1- old
"The old child arrived"

When the subject argument with its nominal modifier [ngwana e moholo -old child] appears with the copulative verb [ke] at the periphery of the clause, the verb [fihla- arrive] above will then be forced into a relative clause with the new subject represented by empty [pro] as demonstrated by the sentence in (17):

$$
\begin{aligned}
& \text { [pro] Ya- fihl -ile -ng ke ngwana e mo- holo } \\
& \text { SM1.REL- arrive -PST -REL COP 1child SM1 NC1- old } \\
& \text { "Who has arrived is the old child" }
\end{aligned}
$$

To establish negation of the subject argument, the negative copulative verb [se] will replace the copulative verb [ke] to appear with the negative morpheme [ha] as illustrated in (18):

$$
\begin{aligned}
& \text { [pro] Ya- fihl -ile -ng ha- se ngwana e mo-holo } \\
& \text { SM1.REL- arrive -PST -REL NEG- COP 1child SM1 NC1- old } \\
& \text { "Who has arrived is not the old child" }
\end{aligned}
$$

As demonstrated by the negative sentence in (18), it is possible to negate the subject argument with its nominal modifier without the contrastive clause. This is because its predicate is in the initial position of the negative clause, separate from a relative clause that now appears in the new subject position of the copulative clause. In the case of negative pseudo-cleft sentences, there is no need to use the contrastive clause to achieve constituent negation. The scope of negation covers the subject together with its nominal modifier. It is therefore clear that constituent negation is possible through the employment of pseudo-cleft sentences.

\subsection{Locative marker [ho] with copulative verb [LI]}

The third type of clause to be examined, in an attempt to negate the subject argument with its nominal modifier, is a clause with the locative marker [ho], where the empty copulative verb [LI] appears with it. Lombard (1985) describes locatives as basic nouns that indicate locality or place. Du Plessis and Visser (1995) describe the locative as a noun phrase that has all the features of any noun phrase, such as the ability to combine with specifiers and complements or appearing in argument position as subject or object of a sentence. There is also the locative of noun class 15, which takes the morpheme [ho] as its subjectival agreement as in (19).

$$
\begin{aligned}
& \text { Ho- j -a ho- monate } \\
& \text { SM15- eat -FV SM15- nice } \\
& \text { "Eating is nice" }
\end{aligned}
$$

Du Plessis and Visser (1995) describe the abstract copulative verb as the abstract verb represented in the lexicon as Cop or [LI]. It appears in sentences with indicative mood mainly taking the adjectival phrases [AdjP], nominal relatives [NPRel], locative noun phrases [NPloc], 
prepositional phrases [PP] and noun phrases [NP] as its complements. It also appears with the agreement of inflection as the sentences in (20) demonstrate.
a.
Barwetsana ba
ba ba-
bC-
"Girls are beautiful"
b. Banna ba
thata
2man SM2.COP REL-hard
"Men are hard"
c. Bana ba sekolo -ng
2child SM2.COP 7school -LOC
"Children are at school”

tle

However, as Du Plessis and Visser (1995) observe, the abstract copulative may express the notion of existence when it appears in existential sentences with an existential empty [pro] as the subject. This copulative may then appear with a noun phrase, which is not exclusive to copulatives. The sentence in (21) illustrates this phenomenon.
(21) Hoi teng Modimo
SM15.COP exist God
"There exists God"

Du Plessis (2010) states that the copulative verb [LI] was originally used to introduce a stative copulative but it has lost its overt form in many African languages. In hypothetical Proto-Bantu this verb has the form [li].The abstract copulative verb is preceded by subject agreement, which might be the first, or second singular or plural or the agreement of any noun class, including the subjectival agreement morpheme [ho]. The purpose of examining constructions with the locative subjectival agreement morpheme [ho] (henceforth locative marker [ho]), is to establish whether it is possible to use such sentence constructions to negate the subject argument. Negation by a negative clause with marker [ho] will be illustrated in three steps.

The subject argument with the adjectival phrase as nominal modifier to be negated is indicated by the sentence in (22) below.

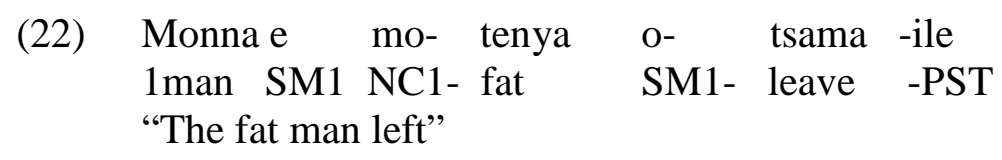

When the marker [ho] appears with the empty category [pro] in the subject position, the verb now appears in the relative clause. The subject monna e motenya "fat man" now becomes the new noun phrase with the relative clause ya-tsamaileng "who has left". The new subject with its nominal modifier will now be the complement of the copulative verb [LI], which appears with the empty category [pro] coindexed with the marker [ho] as illustrated in (23) below. 


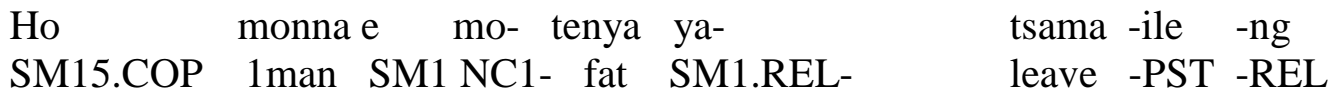

"There exists a fat man who has left"

In order to achieve constituent negation, where the subject argument monna e motenya "fat man" will be negated, the negative morpheme [ha] is employed as indicated in (24) below.

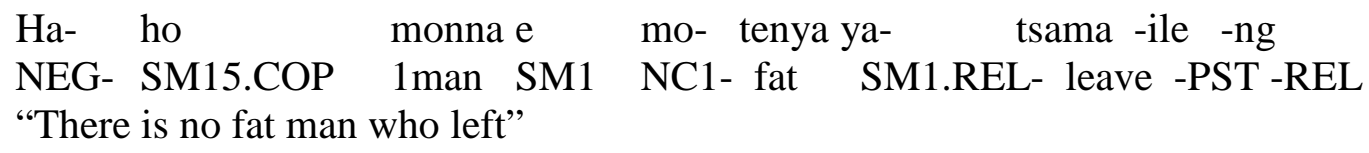

As demonstrated by the sentence in (24) above, it is possible to negate the subject argument with its nominal modifier by employing the negative clause with marker [ho]. However, it is also necessary, as in the case of negative cleft sentences, to use a contrastive clause to isolate and narrow the scope of negation to the subject argument only, as indicated in (25) below.

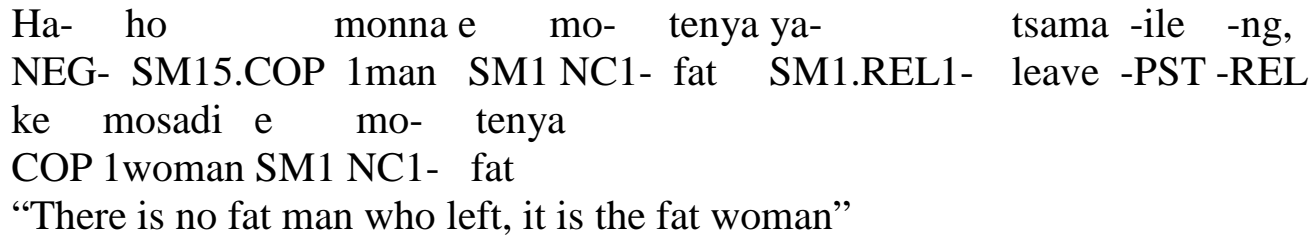

\section{Conclusion}

In this article, the main aim was to examine how Sesotho realizes constituent negation, exploring in particular the subject argument with nominal modifiers. It further examined negation in terms of Haegeman's (1995) Neg-Criterion, the well-formedness condition that determines the distribution and interpretation of negative elements. It has been observed that Sesotho does not have a direct means of negating clausal constituents, such as the subject argument with nominal modifiers. It employs negative clauses such as cleft sentences, pseudocleft sentences and clauses with locative agreement morpheme [ho]. In order to negate a single clausal constituent, Sesotho follows a process comprising of three steps. In the first step, the constituent to be negated, in this case the subject argument with its nominal modifier, has to be placed in focus position by means of the copulative verb [ke] with regard to cleft sentences and pseudo-cleft sentences, and has to be placed in focus position by means of the abstract copulative verb [LI] in the case of sentences with marker [ho].

(26) a. Cleft sentence:

Ke bana ba ba- holo ba- j -el -ng

COP 2child SM2 NC2- old SM1- eat -PST -REL

"It is older children who ate"

b. Pseudo-cleft sentence:

Ya- fihl -ile -ng ke ngwana e mo- holo

SM1.REL- arrive -PST -REL COP 1child SM1 NC1- old

"(The one) who has arrived is the old child" 
c. Clause with marker [ho]:

Ho monna e mo- tenya ya- tsama -ile -ng

SM15.COP 1man SM1 NC1- fat SM1.REL- leave -PST -REL

"There is a fat man who has left"

In the second step, Sesotho employs the negative morpheme [ha] and the negative copulative verb [se] to constitute negation.

(27) a. Cleft sentence:

Ha- se bana ba ba- holo ba- j -el -ng

NEG- COP 2child SM2 NC2- old SM2- eat -PST -REL

"It is not older children who ate"

b. Pseudo-cleft sentence:

Ya- fihl -ile -ng ha- se ngwana e mo- holo SM1.REL- arrive -PST -REL NEG- COP 1child SM1 NC1- old

"(The one) who arrived is not the old child"

c. Clause with marker [ho]:

Ha- ho monna e mo- tenya ya- tsama -ile -ng

NEG- SM15.COP 1man SM1 NC1- fat SM1.REL- leave -PST -REL

"There is no fat man who left"

In this second step, the scope of negation in both negative cleft sentences and clauses with marker [ho] is sentential. It is only with pseudo-cleft negative constructions that local negation is realised in Sesotho without a contrastive clause. With the other two negative constructions, it is necessary to have a third step that employs a contrastive clause to realise constituent negation.

(28) a. Cleft sentence:

Ba- j -el -ng ha- se bana ba ba- holo,

SM2- eat -PST -REL NEG- COP 2child SM2 NC2- old

ke basadi ba ba- holo

COP 2woman SM2 NC2- old

"Who ate are not old children, it is old women"

b. Clause with marker [ho]:

Ha- ho monna e mo- tenya ya- tsama -ile -ng,

NEG-SM15.COP 1man SM1 NC1- fat SM1.REL- leave -PST-REL

ke mosadi e mo- tenya

COP 1woman SM1 NC1-fat

"There is no fat man who left, it is the fat woman"

In other words, the subject arguments above, i.e. bana "children" and monna "man", are negated in context by using contrastive clauses. In terms of Haegemen's (1995) Neg-Criterion, which states that non-negative operators constitute local negation, this article intends to suggest that Sesotho does not have non-negative operators that constitute local or constituent negation. This is because Sesotho negative morphemes are bound morphemes, they are verbal prefixes that always need to appear with their verb stems, and subsequently as verbal prefixes, they cannot 
be generated from nouns or adverbs, as is the case with English. The negative morpheme [ha] in the above examples appears with the negative copulative verb [se] and appears with the abstract copulative verb [LI]. This observation is also supported by the treatment of subject negation in subordinate clauses of Sesotho (Malete 2003), object negation in Sesotho (Malete 2009) and adjunct negation in Sesotho (Malete 2013).

\section{References}

Du Plessis, J.A. and M.W. Visser. 1995. Sesotho Syntax. Stellenbosch Communications in African Languages 3.

Du Plessis, J.A. 2010. Comparative syntax of African Languages of South Africa. Unpublished manuscript. University of Stellenbosch.

Freiden, R. 1995. Review Article: The Minimalist Program. Language 73 (3): 571-582.

Haegeman. LMV. 1995. The Syntax of Negation. Cambridge: Cambridge University Press.

Haegeman, L. 1997. Elements of Grammar. In L. Haegeman (ed). Elements of Grammar: Handbook in Generative Syntax. Netherlands: Kluwer Academic Publishers. pp. 1-72.

Horrocks, G. 1994. Subjects and Configurationality: Modern Greek Clause Structure. Journal of Linguistics 30: 81-109.

Klima, J. 1964. Negation in English. In J.A. Fodor and J.J. Katz (Eds). The structure of language. New Jersey: Prentice - Hall. pp. 246-323.

Laka, I. 1994. On the Syntax of Negation. New York: Garland.

Lasnik, H. 1976. Analyses of Negation in English. Bloomington: Indiana University Linguistics Club.

Lombard, D.P. 1985. Introduction to the Grammar of Northern Sotho. Pretoria: JL van Schaik.

Mettouchi, M. 2005. Nonverbal and verbal negation in Kabyle (Berber): A typological perspective. Amsterdam: John Benjamins Publishing Company. pp. 263-276

Malete, E.N. 1996. Adjacency in Sesotho. Unpublished MA Thesis. University of Stellenbosch.

Malete, E.N. 2003. Subject negation in Sesotho subordinate clauses. South African Journal of African Languages 23:4: 189-198.

Malete, E.N. 2009. Negation of the object in Sesotho. Macrolinguistics 3 (3): 67-83.

Malete, E.N. 2013. Negation of Adjuncts in Sesotho. In G. Rata (ed.). Linguistics Studies of Human Languages. Athens: ATINER. pp.35-54.

Madadzhe, R.N. 1997. The Copulative in Venda. Unpublished D Litt Dissertation. University of Stellenbosch. 
Madadzhe R.N and T.M. Matla. 2002. The negative morphemes ha and a in Sesotho and Tshivenda. South African Journal of African Languages 22 (3): 224-238

McCloskey, J. 1997. Subjecthood and Subject Positions. In L. Haegeman (ed.). Elements of Grammar: Handbook in generative Syntax. Netherlands: Kluwer Academic Publishers.

Ngonyani, D. 2002. Sentential negation and verb movement in Bantu Languages. Berkeley Linguistics Society 28: 201-212.

Tanda, V.A. and A.N. Neba. 2005. Negation in Mokpe and two related coastal Bantu languages of Cameroon. African Study Monographs 26 (4): 201-219.

Richards, J. 1985. Longman Dictionary of Applied Linguistics. London: Longman Zanuttini, R. 1997. Negation and Clausal Structure. A Comparative Study of Romance Languages. Oxford: Oxford University Press. 